\title{
Investigation of Structural and Physical Properties of Composite Catalyst Support with Exfoliated Graphite Additive
}

\author{
E.A. Pushina*, A.R. Karaeva, I.G. Solomonik, S.A. Urvanov, V.Z. Mordkovich \\ Technological Institute for Superhard and Novel Carbon Materials (FSBI TISNCM), \\ 7 a Tsentralnaya street, Troitsk, Moscow, 108840, Russia
}

* Corresponding author. Tel.: +7 964563 722 57; fax: +7 499400 6260; E-mail: katyazhu@tisnum.ru

\begin{abstract}
The methodology for manufacturing composite catalyst supports comprising 50 wt. \% exfoliated graphite by mold pressing was developed. The technique of wetting a relatively hydrophobic powder with liquid to obtain uniform paste for press machine was proposed and tested. The dependencies of the samples density on the compacting pressure were obtained. The structural characterization was done, i.e. specific surface area, porosity, micro- and mesopores volume, pore size distribution were measured. It was found that obtained samples have a specific surface area of about $340 \mathrm{~m}^{2} / \mathrm{g}$, total pore volume of about $0.28 \mathrm{~cm}^{3} / \mathrm{g}$ at a true density of $2.3-2.5 \mathrm{~g} / \mathrm{cm}^{3}$, practically regardless of compacting pressure in the range from 16 to $230 \mathrm{MPa}$. The thermal conductivity coefficients of the sample pressed at $230 \mathrm{MPa}$ were 3.6 and $12.2 \mathrm{~W} /(\mathrm{m} \cdot \mathrm{K})$ along the cylinder axis and perpendicular to it, respectively. This anisotropy is due to specific preferential orientation of the heatconducting component. The composite reveals similar anisotropy in strength. The strength was measured as 39.4 and $87.6 \mathrm{~N} /$ granule along the axis of the granule and perpendicular to it, respectively. The results of the paper demonstrate that a contradictive task of combining high specific surface area, strength and thermal conductivity can be realized in one sample, which is important for catalysis applications.
\end{abstract}

Keywords

Exfoliated graphite; composite material; thermal conductivity; catalyst.

(c) E.A. Pushina, A.R. Karaeva, I.G. Solomonik, S.A. Urvanov, V.Z. Mordkovich, 2020

\section{Introduction}

One of the most effective and rational means of accelerating chemical processes is catalysis [1-3]. Heterogeneous catalysis is much more widespread in industry than homogeneous one [1]. Composition and chemical structure of catalysts are extremely diverse. They can be in elemental form or in the form of various compounds, such as oxides, sulfides, metal complexes with organic ligands. Supported catalysts are often used, resulting from the distribution of a catalytically active component on a support or in its volume $[4,5]$. Materials with a highly developed surface are used to create a support [1], and usually the support is not completely inert during the process [6]. Since heterogeneous catalytic reactions are often highly exothermic, heat-conducting additives are introduced to boost a catalytic system. For example, aluminum and its alloys [7-9], metal foams [10-12] or carbons such as nanofibers, etc. $[13,14]$ are used as heat-conducting additives in the Fischer-Tropsch synthesis $[15,16]$.
Aluminum metal forms an effective heat-conducting lattice, which significantly improves the properties of the catalyst. The main disadvantages of using structured blocks, foamed metals or other highly conductive materials such as silicon carbide [17, 18] are low specific surface area and the complexity of the use of some active components.

In present work nanostructured carbon in the form of exfoliated graphite was used as a heat-conducting additive in the composition of a catalyst support used in the Fischer-Tropsch synthesis.

The aim of this paper was to study the structural and physical properties of a composite catalyst support prepared by mold pressing with use of exfoliated graphite as a heat-conducting component.

\section{Experimental}

Composite catalyst supports comprising 50 wt. \% exfoliated graphite (powder provided by UNIKHIMTEK), 20 wt. \% boehmite Disperal P2, 
30 wt. \% ammonium form of zeolite Zeolyst CP814c were prepared by mold pressing (high pressure tabletizing). The composition values above indicate percentage of components in a dry mixture. Sample preparation consisted of

1) mixing of boehmite, zeolite and graphite in the indicated weight ratios;

2) preparation of the liquid phase: a solution of nitric acid $\mathrm{HNO}_{3}(64 \%)$ and TEG (triethylene glycol $\mathrm{C}_{6} \mathrm{H}_{14} \mathrm{O}_{4}$ ). For $10 \mathrm{~g}$ of dry mixture we took $0.45 \mathrm{ml}$ of $\mathrm{HNO}_{3}$ (concentration of $64 \%$ ), $1.5 \mathrm{~g}$ of TEG and $5 \mathrm{ml}$ of $\mathrm{H}_{2} \mathrm{O}$;

3) addition of liquid phase to the mixture of boehmite, zeolite and graphite;

4) manual mixing until a homogeneous paste is formed;

5) mold pressing of the samples at different pressures in the range from 10 to $660 \mathrm{MPa}$;

6 ) heat treatment of granulated samples in a muffle furnace at the temperature up to $300{ }^{\circ} \mathrm{C}$ and exposition under these conditions.

The composition of the catalyst support corresponds to the composition of an extruded catalyst support, which has previously proved to be effective in the Fischer-Tropsch synthesis and used as a standard. The choice of the main components of the support is due to binding properties of the boehmite, acidic centers of a zeolite, and high thermal conductivity of graphite. TEG in the liquid phase is used as a plasticizer, while $\mathrm{HNO}_{3}$ is used for peptization of boehmite. Samples were pressed in molds. The resulting samples were cylinders with a diameter of $2.5 \mathrm{~mm}$ and a height of $3.5 \mathrm{~mm}$.

The specific surface area and pore size distribution were determined by Autosorb-1c instrument. The true density of the samples was determined by Ultrapyc 1200e gas pycnometer (Quantachrome Instruments). The thermal conductivity was calculated from the heat capacity and thermal diffusivity determined by DSC 8000 differential scanning calorimeter and an LFA 457 MicroFlash instrument from NETZSCH-Gerätebau $\mathrm{GmbH}$, respectively. The strength of the samples was determined by DiaTest-S instrument. The microstructure of the samples was investigated by Tescan Vega 3 scanning electron microscope.

\section{Results and Discussion}

The mold pressing of the catalyst supports was carried out in the pressure range of 10-660 MPa. Pure graphite was used as a reference compound for checking the quality of the obtained samples. One of the most important parameters for the operation of the catalyst is the apparent (geometric) density obtained as the ratio of a geometric volume to weight. The results of experiments to determine the apparent density are presented in the "density-pressure" coordinates (Fig. 1).

The density-pressure dependence curve for graphite samples comes on a plateau at appr. $2 \mathrm{~g} / \mathrm{cm}^{3}$ after reaching a pressure of 250-300 MPa. The pressure dependence of the apparent density for the catalyst support samples (see Fig. 1) is generally similar to the dependence for reference graphitic granule. The calcined support density-pressure dependence shows a similar plateau at appr. $1.5 \mathrm{~g} / \mathrm{cm}^{3}$. In addition, the density of granules during calcination decreases due to desorption of adsorbed and chemically bound liquid (TEG, acid, water, etc.).

Channels and pores are formed during calcination. It was noted that the drop-by-drop introduction of liquid phase gives nonuniform mixing: the mixture is divided into well-moistened lumps and dry powder. Therefore, the introduction of the liquid phase was made by spraying of smallest particles through an atomizer, which makes it possible to obtain a uniformly homogeneous paste for pressing.

Samples were prepared at pressures of 16, 24, $230 \mathrm{MPa}$ (at the beginning, at the inflection and plateau of the curve respectively) to compare structural

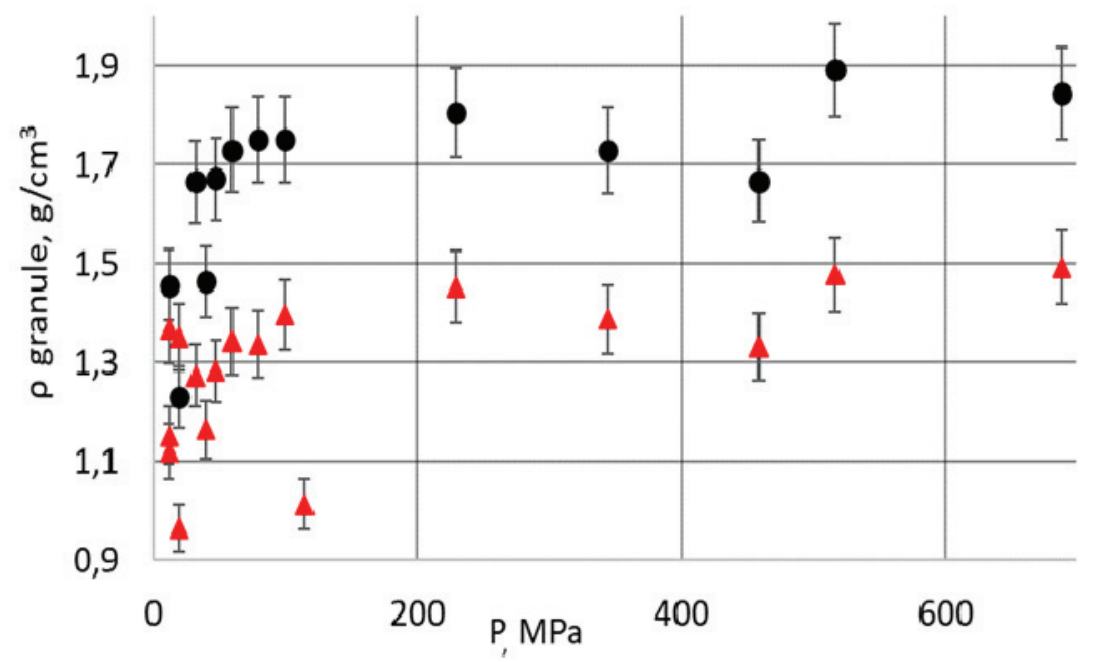

Fig. 1. Dependence of apparent density on compacting pressure for composite supports comprising $50 \mathrm{wt}$. \% exfoliated graphite: $\Delta$ - calcined samples; $\boldsymbol{\bullet}_{-}$raw samples 
properties of the samples with the highest difference in apparent densities. Adsorption isotherms were obtained as a result of measurements by Autosorb-1c device. The resulting structural properties are shown in Table 1.

Based on data given in Table 1, it can be concluded that changes in pressure leads to similar calculated values of the structural properties.

Sorption curves, integral distribution of the specific volume via radius and desorbing volume dependence via radius are shown in Fig. 2, 3 and 4, respectively. As noted above, no significant differences were observed at different pressures.
Table 1

Porous system properties of composites produced with different compacting pressures

\begin{tabular}{cccc}
\hline $\begin{array}{c}\text { Compacting } \\
\text { pressure, } \\
\mathrm{MPa}\end{array}$ & $\begin{array}{c}\text { Specific } \\
\text { surface area, } \\
\mathrm{m}^{2} / \mathrm{g}\end{array}$ & $\begin{array}{c}\text { Total pore } \\
\text { volume, } \\
\mathrm{cm}^{3} / \mathrm{g}\end{array}$ & $\begin{array}{c}\text { True } \\
\text { density, } \\
\mathrm{g} / \mathrm{cm}^{3}\end{array}$ \\
\hline 16 & 339 & 0.281 & 2.24 \\
24 & 342 & 0.283 & 2.33 \\
230 & 345 & 0.282 & 2.54 \\
\hline
\end{tabular}

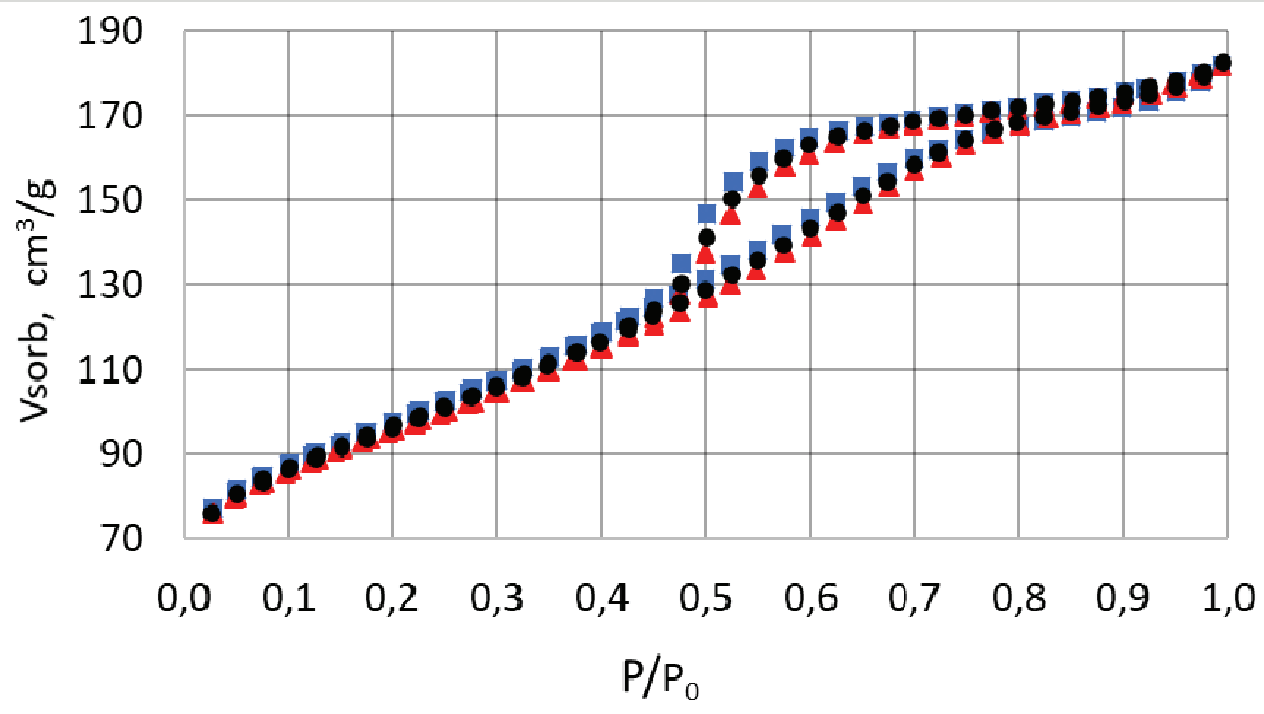

Fig. 2. Sorption curves:

$\square-P=230 \mathrm{MPa} ; \bullet-P=24 \mathrm{MPa} ; \boldsymbol{\Delta}-P=16 \mathrm{MPa}$

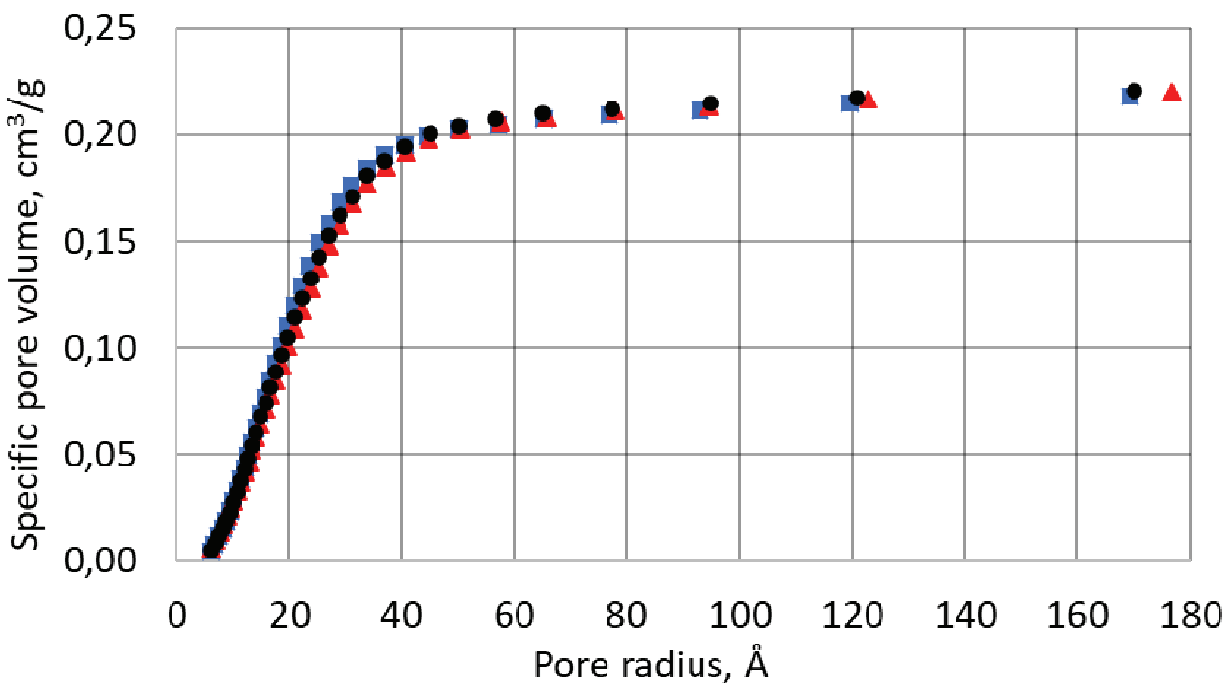

Fig. 3. Integral distribution of the specific volume via radius: $\square-P=230 \mathrm{MPa} ;-P=24 \mathrm{MPa} ; \Delta-P=16 \mathrm{MPa}$ 


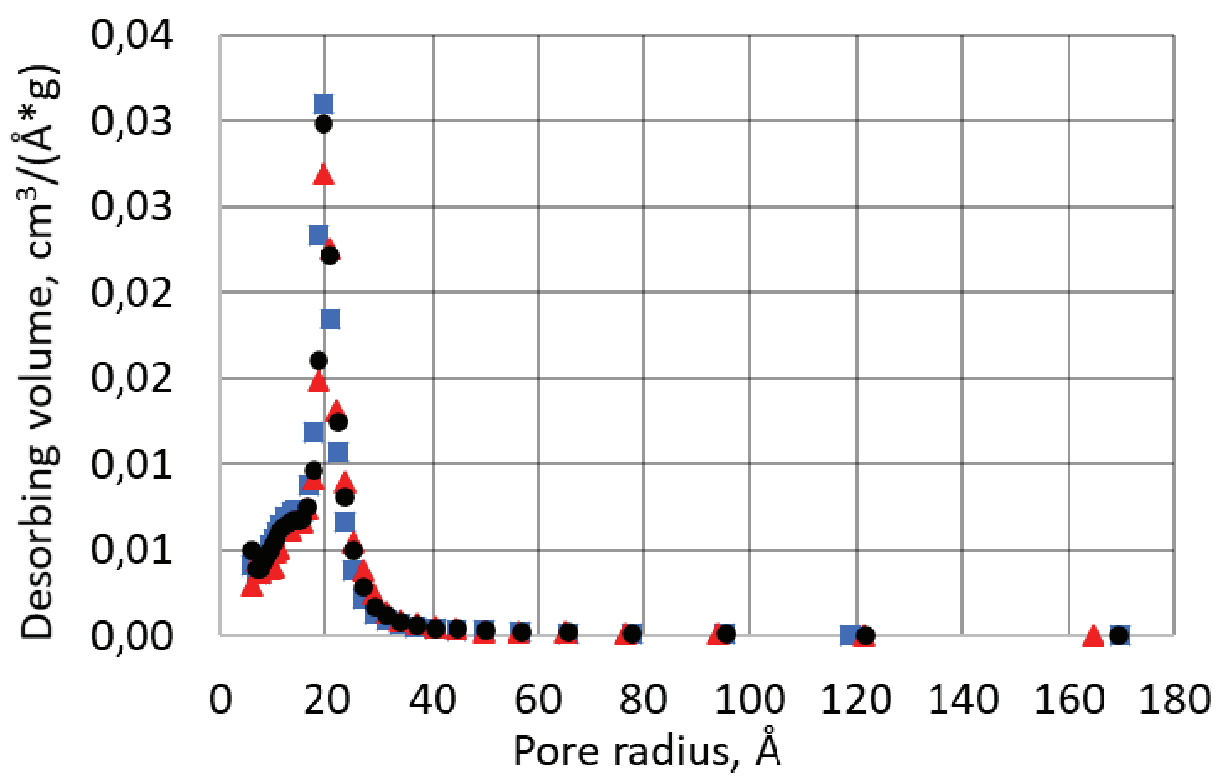

Fig. 4. Desorbing volume dependence via radius: $-P=230 \mathrm{MPa} ;-P=24 \mathrm{MPa} ; \Delta-P=16 \mathrm{MPa}$

The values of true density were determined by pycnometric method (see Table 1). According to the results, the true density increases with the growth of pressure. It correlates with the apparent density in case of the same geometric dimensions of the samples.

Physical properties of the samples such as strength and thermal conductivity were investigated. It was noted that the strength of the samples pressed at 16 and $24 \mathrm{MPa}$ was below the measurement range. Strength tests revealed an anisotropy of the samples pressed at $230 \mathrm{MPa}$. The average strength values along the axis of the cylinder were about $39.4 \mathrm{~N} /$ granule; perpendicular to the axis $-87.6 \mathrm{~N} /$ granule (Table 2).

The average thermometric conductivity of the samples pressed at $230 \mathrm{MPa}$ was $2.5 \mathrm{~mm}^{2} / \mathrm{s}$ and $9.2 \mathrm{~mm}^{2} / \mathrm{s}$, and the thermal conductivity was 3.6 and $12.2 \mathrm{~W} /(\mathrm{m} \cdot \mathrm{K})$ along the cylinder axis and perpendicularly, respectively.

The highest thermal conductivity is observed in perpendicular direction of the samples. It can be explained by the well-known tendency of graphite flakes to get preferential orientation across the direction

Table 2

Strength measurements for samples pressed at $230 \mathrm{MPa}$

Sample

\begin{tabular}{lllllllll} 
number & 1 & 2 & 3 & 4 & 5 & 6 & 7 & 8 \\
\hline
\end{tabular}

Force,

$\begin{array}{lllllllll}\mathrm{N} / \text { granule } & 51.7 & 47.0 & 40.2 & 26.6 & 32.9 & 38.2 & 90.8 & 84.4\end{array}$ of pressing as it happens, for example, during formation of graphitic foils. Measurements of thermometric conductivity and thermal conductivity for samples pressed at $230 \mathrm{MPa}$ are presented in Table 3. This measurement demonstrates that a contradictive task of combining high specific surface area, strength and thermal conductivity can be realized in one sample. It is possible that the use of other, more disperse forms of graphite such as multilayer graphenes can give even better result in the future.

Table 3

\section{Measurements of thermometric conductivity and thermal conductivity for samples pressed at $230 \mathrm{MPa}$}

\begin{tabular}{cccc}
\hline $\begin{array}{c}\text { Sample } \\
\text { number }\end{array}$ & $T,{ }^{\circ} \mathrm{C}$ & $\begin{array}{c}\text { Thermometric } \\
\text { conductivity, } \mathrm{mm}^{2} / \mathrm{s}\end{array}$ & $\begin{array}{c}\text { Thermal } \\
\text { conductivity, } \\
\mathrm{W} /(\mathrm{m} \cdot \mathrm{K})\end{array}$ \\
\hline 1 & 2 & 3 & 4 \\
\hline 1 & 124.8 & 2.57 & 3.4 \\
& 152.1 & 2.42 & 3.2 \\
& 176.8 & 2.32 & 3.0 \\
& 201.5 & 2.24 & 2.9 \\
& 226.3 & 2.16 & 2.8 \\
& 251.1 & 2.09 & 2.7 \\
2 & 125.4 & 3.09 & 4.5 \\
& 150.9 & 2.93 & 4.3 \\
& 175.8 & 2.81 & 4.1 \\
\hline
\end{tabular}


Continuation of the Table 3

\begin{tabular}{|c|c|c|c|}
\hline 1 & 2 & 3 & 4 \\
\hline & 200.7 & 2.73 & 4.0 \\
\hline & 225.6 & 2.61 & 3.8 \\
\hline & 250.6 & 2.53 & 3.7 \\
\hline \multirow[t]{6}{*}{3} & 125.1 & 2.93 & 4.2 \\
\hline & 151.2 & 2.80 & 4.0 \\
\hline & 176.2 & 2.70 & 3.9 \\
\hline & 201 & 2.59 & 3.7 \\
\hline & 226 & 2.50 & 3.6 \\
\hline & 250.9 & 2.42 & 3.5 \\
\hline \multirow[t]{6}{*}{4} & 125.4 & 2.79 & 4.0 \\
\hline & 150.7 & 2.71 & 3.8 \\
\hline & 175.7 & 2.58 & 3.7 \\
\hline & 200.7 & 2.49 & 3.5 \\
\hline & 225.7 & 2.36 & 3.3 \\
\hline & 250.7 & 2.31 & 3.3 \\
\hline \multirow[t]{6}{*}{5} & 124.0 & 2.61 & 3.8 \\
\hline & 151.7 & 2.45 & 3.5 \\
\hline & 176.7 & 2.36 & 3.4 \\
\hline & 201.5 & 2.26 & 3.3 \\
\hline & 226.3 & 2.19 & 3.2 \\
\hline & 251.2 & 2.12 & 3.1 \\
\hline \multirow[t]{6}{*}{6} & 125.1 & 10.25 & 13.6 \\
\hline & 150.7 & 9.83 & 13.0 \\
\hline & 175.9 & 9.24 & 12.3 \\
\hline & 200.9 & 8.94 & 11.9 \\
\hline & 225.8 & 8.45 & 11.2 \\
\hline & 250.8 & 8.26 & 11.0 \\
\hline
\end{tabular}

\section{Conclusions}

A study of structural and physical properties of composite catalyst supports comprising 50 wt. \% exfoliated graphite by mold pressing was carried out. The technique of wetting a relatively hydrophobic powder with liquid to obtain uniform paste for press machine for a preparation of composite supports was proposed and tested. It was found that the obtained composites have a specific surface area of about $340 \mathrm{~m}^{2} / \mathrm{g}$, total pore volume of about $0.28 \mathrm{~cm}^{3} / \mathrm{g}$ at a true density of $2.3-2.5 \mathrm{~g} / \mathrm{cm}^{3}$, practically regardless of compacting pressure in the range from 16 to $230 \mathrm{MPa}$.
The thermal conductivity coefficients of the sample pressed at $230 \mathrm{MPa}$ were 3.6 and $12.2 \mathrm{~W} /(\mathrm{m} \cdot \mathrm{K})$ along the cylinder axis and perpendicular to it, respectively. This anisotropy is due to specific preferential orientation of the heat-conducting component. The composite reveals similar anisotropy in strength. The strength was measured as 39.4 and $87.6 \mathrm{~N} /$ granule along the axis of the granule and perpendicular to it, respectively. The results of the paper demonstrate that a contradictive task of combining high specific surface area, strength and thermal conductivity can be realized in one sample, which is important for catalysis applications.

\section{Acknowledgements}

The study was carried out using the equipment of the FSBI TISNCM Shared-Use Equipment Center (SUEC) "Research of Nanostructured, Carbon and Superhard Materials".

\section{References}

1. Krylov O.V. Geterogennii kataliz [Heterogeneous catalysis]. Moscow, Akademkniga publ, 2004. 679 p. (Rus)

2. Romanovsky B.V. Osnovyi kataliza [Fundamentals of catalysis] Moscow, Binom. Laboratory of knowledge, 2014. 172 p. (Rus)

3. Bayramov V.M. Osnovyi kinetiki $i$ kataliza [Fundamentals of Chemical Kinetics and Catalysis] Moscow, Publishing Center Academy, 2003. 256 p. (Rus)

4. Sartipi S., van Dijk J.E., Gascon J., Kapteijn F. Toward bifunctional catalysts for the direct conversion of syngas to gasoline range hydrocarbons: H-ZSM-5 coated Co versus H-ZSM-5 supported Co. Applied Catalysis. A., 2013, 456, 11-22.

5. Freitez A., Pabst K., Kraushaar-Czarnetzki B., Schaub G. Single-Stage Fischer-Tropsch Synthesis and Hydroprocessing: The Hydroprocessing Performance of $\mathrm{Ni} / \mathrm{ZSM}-5 / \gamma-\mathrm{Al}_{2} \mathrm{O}_{3}$ under Fischer-Tropsch Conditions. Industrial \& Engineering Chemistry Research, 2011, 50, 13732-13741.

6. Solomonik I.G., Gryaznov K.O., Skok V.F., Mordkovich V.Z., Formation of surface cobalt structures in SiC-supported Fischer-Tropsch catalysts. RSC Advances, 2015, 5, 78586-78597.

7. Merino D., Sanz O., Montes M. Effect of catalyst layer macroporosity in high-thermalconductivity monolithic Fischer-Tropsch catalysts. Fuel, 2017, 210, 49-57.

8. Merino D., Sanz O., Montes M. Effect of the thermal conductivity and catalyst layer thickness on the 
Fischer-Tropsch synthesis selectivity using structured catalysts. Chemical Engineering Journal, 2017, 327, 1033-1042

9. Kim H.-J., Ryu J.-H., Joo H., Yoon J., Jung H., Yang J.-I. Mass- and heat-transfer-enhanced catalyst system for Fischer-Tropsch synthesis in fixed-bed reactors. Research on Chemical Intermediates, 2008, 34(8-9), 811-816.

10. Fratalocchi L., Visconti C.G., Groppi G., Lietti L., Tronconi E. Intensifying heat transfer in Fischer-Tropsch tubular reactors through the adoption of conductive packed foams. Chemical Engineering Journal, 2018, 349, 829-837.

11. Sheng M., Yang H., Cahela D.R., Yantz Jr W.R., Gonzalez C.F., Tatarchuk B.J. High conductivity catalyst structures for applications in exothermic reactions. Applied Catalysis A: General, 2012, 445-446, 143-152.

12. Park J. C., Roh N. S., Chun D. H., Jung H., Yang J.-I. Cobalt catalyst coated metallic foam and heatexchanger type reactor for Fischer-Tropsch synthesis. Fuel Processing Technology, 2014, 119, 60-66.

13. Zhu J., Yang J., Lillebø A. H., Zhu Y., Yu Y., Holmen A., Chen, D. Compact reactor for Fischer-
Tropsch synthesis based on hierarchically structured Co catalysts: Towards better stability. Catalysis Today, 2013, 215, 121-130.

14. Maitlis P.M., Klerk A. (Eds.) Greener Fischer-Tropsch Processes. Weinheim: Wiley-VCH. 2013. 372 p.

15. Dry M., Steynberg A. (Eds.) Fischer-Tropsch Tech. Stud. Sur. Sci. and Cat. Amst.: Elsevier B.V. 2004. 700 p.

16. Kim J., Nese V., Joos J., Jeske K., Duyckaerts N., Pfänderc N., Prieto G. Directional freeze-cast hybridbackbone meso- macroporous bodies as micromonolith catalysts for gas-toliquid processes. Journal of Materials Chemistry A, 2018, 6(44), 21978-21989.

17. Hilmen M., Bergene E., Lindvåg O.A., Schanke D., Eri S., Holmen A. Fischer-Tropsch synthesis on monolithic catalysts of different materials. Catalysis Today, 2001, 69, 227-232.

18. Asalieva E., Gryaznov K., Kulchakovskaya E., Ermolaev I., Sineva L., Mordkovich V. FischerTropsch synthesis on cobalt-based catalysts with different thermally conductive additives. Applied Catalysis A: General. 2015, 505, 260-266.

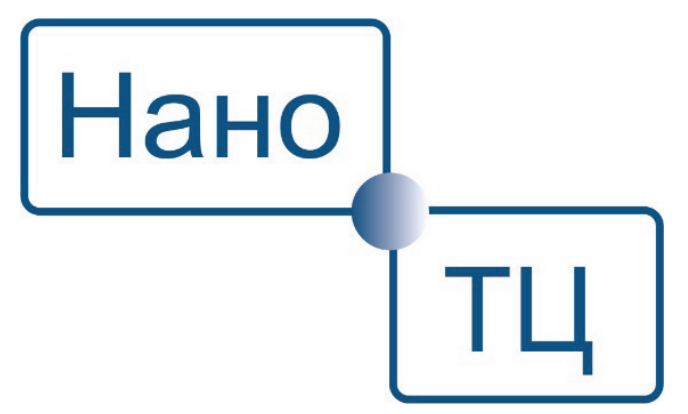

$$
\begin{array}{ll}
\text { E-mail: } & \text { nanotam@yandex.ru } \\
\text { Address: } & 392000, \text { Russia Tambov, } \\
& \text { Sovetskaya 51, } \\
& \text { OOO "NanoTechCenter" }
\end{array}
$$

Tel.: $\quad+7$ (4752) 63-55-22

$$
+7 \text { (4752) 63-92-93 }
$$

NanoTechCenter was founded in 2006. The company produces multi-walled carbon nanotubes (CNTs), multi- and small-layer graphene nanoplates (GNPs) and products based on them, as well as equipment for their synthesis. These materials can find various applications, including, building materials, additives for lubricants, electric heaters, some household appliances, supercapacitor electrodes, as adsorbents for environmental purposes (water treatment, soil remediation, engineering barriers in deep geological burials of radioactive waste). 